\title{
Crystallization in Rapidly Quenched Fe-B-Si System with Additions of C and Cu
}

\author{
Irena Janotováa ${ }^{a}$, Juraj Zigo ${ }^{a}$, Peter Švec ${ }^{a}$, Igor Mat'ko ${ }^{a}$, Dušan Janičkoviča , Peter Švec Sra \\ a'Institute of Physics, Slovak Academy of Sciences - SAV, Bratislava, Slovakia
}

Received: October 20, 2014; Revised: October 6, 2015

\begin{abstract}
Glass formability and phase transformations in rapidly quenched ferromagnetic nano-structured $\left(\mathrm{Fe}_{85} \mathrm{~B}_{15-\mathrm{x}} \mathrm{Si}_{\mathrm{x}}\right)_{98-\mathrm{y}} \mathrm{C}_{2} \mathrm{Cu}_{\mathrm{y}}$ (where $\mathrm{x}=0 ; 5$ and $\left.\mathrm{y}=0 ; 1\right)$ systems were investigated. The consecutive crystallization stages of bcc-Fe and borides were determined by resistometry, differential scanning calorimetry and by thermogravimetry, where the values of important transformation parameters were estimated and mutually correlated with the results from the structure analysis by TEM and XRD. Morphology of the nano-sized Fe grains in amorphous matrix and their transformation to borides matrix was observed by TEM in dependence on the chemical composition and thermal treatment. The effects of systematic alloying on the transformation process and on the resulting structure have been correlated with selected magnetic properties of the samples after suitable annealing.
\end{abstract}

Keywords: metallic glasses, soft magnetic materials, nanocrystalline structure

\section{Introduction}

Nanocrystalline soft magnetic Fe-B-(Si) based alloys due to their structure and chemical composition exhibit useful magnetic benefits such as a high saturation magnetic flux density $\left(B_{S}\right)$, high permeability $\left(\mu_{E}\right)$ and low coercive force $\left(H_{C}\right)$ as well as almost zero magnetostriction $(\lambda)$. The ferromagnetic bcc-Fe grains in reduced size well below $100 \mathrm{~nm}$ are immersed in amorphous matrix ${ }^{1-7}$. The Fe-B-(Si) systems in combination with a small amount of $\mathrm{C}$ (as well as with addition of $\mathrm{Cu}$ ) also have been frequently studied. Alloying with $\mathrm{Si}$ and $\mathrm{Cu}$ is known to improve magnetic and thermal properties of this system, making these nanostructured materials suitable for many electrical, magnetic and other power applications with lowered material $\cos ^{6-10}$. These additions into the Fe-B system improve the glass forming ability and the resulting physical properties. Optimization of the structure by adding a small amount of $\mathrm{Cu}$ leads to the enhancement of formation of large number of small clusters from amorphous matrix, creating thus a greater number of smaller crystalline bcc-Fe grains ${ }^{6,11-13}$. A proper combination of these alloying elements into the eutectic Fe-B system can lead to the improved glass forming ability and then resulting physical properties, which depend on the final crystalline structure and its proportion to the amorphous matrix: the important and requested properties depend on the final structure of ferromagnetic crystals as well as on their volume content in the remaining amorphous matrix. Only a few combinations of B-(Si)-C additions have been studied so far ${ }^{12}$. In this work we studied the physical properties - transformation of ferromagnetic phases in $\left(\mathrm{Fe}_{85} \mathrm{~B}_{15-\mathrm{x}} \mathrm{Si}_{\mathrm{x}}\right)_{98-\mathrm{y}} \mathrm{C}_{2} \mathrm{Cu}_{\mathrm{y}}$ systems, where $\mathrm{x}=0 ; 5$ and $\mathrm{y}=0 ; 1$ with the aim to maintain the quality found in systems containing more expensive additions. Present work is oriented onto the characterization of these simple metallic systems. The compositional tuning of the Curie temperature $T_{C}$ of the amorphous phase, the onset of

*e-mail: irena.janotova@savba.sk
bcc-Fe phase crystallization - $T_{X}$, the temperature of maximal rate of phase transformation $T_{M A X}$, and also the changes of activation energies of ferromagnetic $\mathrm{Fe}$ phase were investigated. The phase evolution from amorphous matrix by controlled isothermal annealing and/or linear heating is shown. The thermal stability and thermal parameters of the studied alloys were studied. With the methods described in Jen \& Yang ${ }^{14}$, Blázquez et al. ${ }^{15}$, Yuan et al. ${ }^{16}$ and Švec \& Kristiakova ${ }^{17}$ it was possible to determine the activation energy in the course of crystallization reaction from the isothermal resistivity measurements.

\section{Experimental Procedure}

The amorphous ribbons $6 \mathrm{~mm}$ wide and $\sim 20 \mu \mathrm{m}$ thick were prepared by the planar flow casting (PFC) technique. Chemical analysis of their composition was performed by the inductionally coupled plasma spectroscopy. The sequence of crystallization stages from the amorphous structure was investigated on linearly heated as well as isothermally annealed samples. The kinetic parameters $\left(T_{X}(10 \mathrm{~K} / \mathrm{min})\right.$, $\left.T_{M A X}(5,10,20,40,80 \mathrm{~K} / \mathrm{min}), T_{C}(10 \mathrm{~K} / \mathrm{min})\right)$ were studied by differential scanning calorimetry (DSC7 Perkin Elmer) and by thermogravimetry with the small applied magnetic field (TGA7 Perkin Elmer), both in protective argon atmosphere. The activation energies $E_{A K T}$ were determined from the temperatures of maximal rate of phase transformation $T_{M A X}$ using different heating rates by DSC. Dependencies of the electric resistivity on time and temperature were measured by the high precision four-point probe method in terms of relative electric resistivity (standardized ratio $R(T) / R\left(T_{0}=300 \mathrm{~K}\right.$ ) or $R(t) / R(t=5 \mathrm{sec})$ ) under high vacuum. Structure of the as-cast samples as well as of the isothermally annealed ones was investigated by the X-ray diffraction (XRD) using Bruker D8 diffractometer using $\mathrm{Cr} K_{\alpha}$ radiation and by transmission electron microscopy (TEM) using JEOL 2000FX operating 
at $200 \mathrm{kV}$. The structure of the samples and the phases present were identified by in-situ TEM observation during both isothermal (30, 60, 90, $150 \mathrm{~min})$ and in-situ XRD linear annealing $(2 \mathrm{~K} / \mathrm{min})$ of selected samples using $\mathrm{Cu} K_{\alpha}$ radiation.

\section{Results and Discussion}

The transformation from amorphous state into the crystalline one takes place typically in more than one stage - at first the ferromagnetic phases crystallizes, and subsequently the evolution of borides phases from the remaining amorphous matrix appears. The crystallization onset of the samples studied can be seen in Figure 1a as smooth decrease of normalized heat flow. Shape of the transformation curves peaks reflects the nature and the kinetics of these phase changes. The Fe-B-C alloy is an exception to this behavior as it exhibits only a single stage transformation at higher temperatures. This effect is similar to the one observed in Fe-B-P system ${ }^{18,19}$ - of additions of $\mathrm{Cu}$ to basic $\mathrm{Fe}-\mathrm{B}-\mathrm{P} / \mathrm{Fe}-\mathrm{B}-\mathrm{C}$ systems, which influences the temperatures of crystallizations onsets. The crystallization in the Fe-B-C sample with addition of 1 at. $\% \mathrm{Cu}$ (Figure 1a) splits into two stage transformation, where the first stage appears at lower temperatures. Shape of the transformation curves reflects

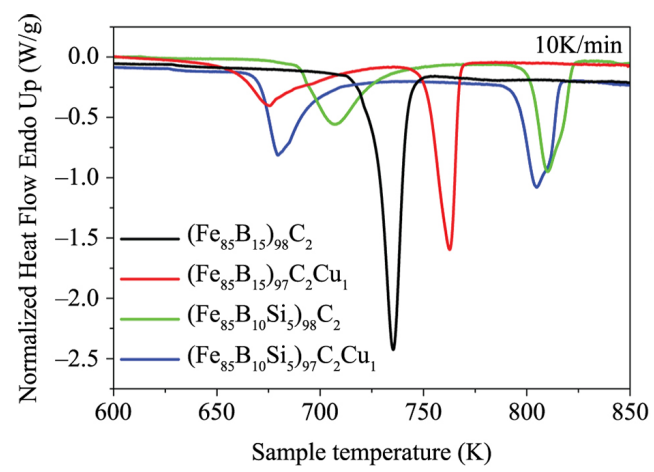

(a)

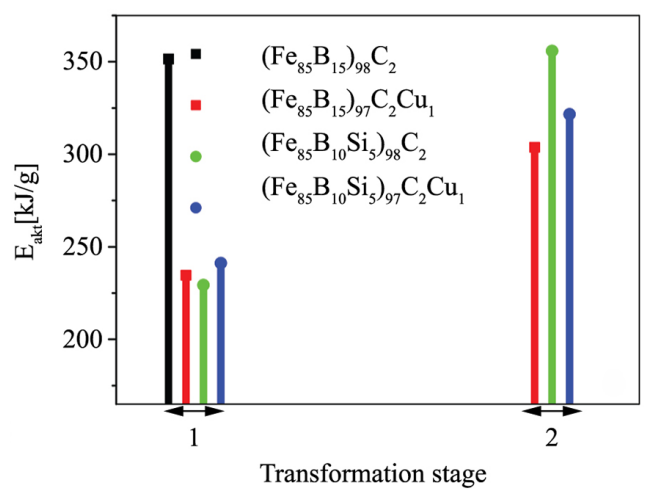

(b)

Figure 1. (a) Temperature dependence of normalized heat flow measurement by DSC, for the systems with different chemical composition, inset shows the effect of separated additions in the base composition. (b) Activation energies for each transformation stage in studied systems determined by Kissinger method (DSC), accuracy of $\mathrm{E}_{\mathrm{akt}}$ determination is better than $+/-5 \mathrm{~kJ} / \mathrm{mol}$. the nature and the kinetics of these phase changes. Other studied alloys exhibit two stage transformations where the first stage takes place below $700 \mathrm{~K}$ and has the character of nanocrystallization ${ }^{20}$. The addition of $\mathrm{Si}$ affects the stability of the amorphous remains, which was assessed by the temperature (time) interval between the two subsequent different transformations stages as studied by DSC.

Using the measured values of $T_{M A X}$ for both transformation stages in all samples, the activations energies $E_{A K T}$ were determined by the Kissinger method. The influence of chemical composition on the $E_{A K T}$ of the transformations is shown in Figure 1b: the value for the first reaction lies above $225 \mathrm{~kJ} / \mathrm{mol}$ and for the second one between $300-360 \mathrm{~kJ} / \mathrm{mol}$, the impact of additions is unsystematic. Exception is found in the basic Fe-B-Si system, where the activation energy for this "polymorphous" transformation is around $350 \mathrm{~kJ} / \mathrm{mol}$.

By the alloying it is possible to tune the structural and kinetic properties as well as the Curie temperature of the amorphous phase. The transition from ferromagnetic to paramagnetic state as measured by thermogravimetry (TGA) is seen in Figure 2. The downfall and the rise of the magnetic weight indicate the temperature of the change of magnetization and the growing amount of ferromagnetic phase. Comparison of the results shows an important influence of $\mathrm{Si}$ and $\mathrm{Cu}$ on the phase transformation process - the $T_{C}$ for Fe-B-Si-C-Cu system is about $625 \mathrm{~K}$.

The thermal parameters and the different character of the transformations were also observed by the measurements of relative electrical resistivity dependency on temperature and time. Different kinetics of the first crystallization stage as well as the shift of $T_{X}$ in temperature is shown for different compositions in Figure 3a. The temperature chosen for the $\mathrm{XRD}$ analysis $(633 \mathrm{~K})$ is marked in the figure, as well. Kinetics of structural changes was observed also by the resistivity evolution during isothermal annealing (Figure 3b), at $673 \mathrm{~K}$ for Fe-B-C sample and at $633 \mathrm{~K}$ for the other investigated samples. Higher annealing temperature is shown for the latter one, because this sample exhibits higher temperature of crystallization onset $\left(T_{X}\right.$ higher than $\left.700 \mathrm{~K}\right)$. By this experiment the annealing regime for the TEM observation by in-situ annealing as well as the times for the observation of final structure were chosen.

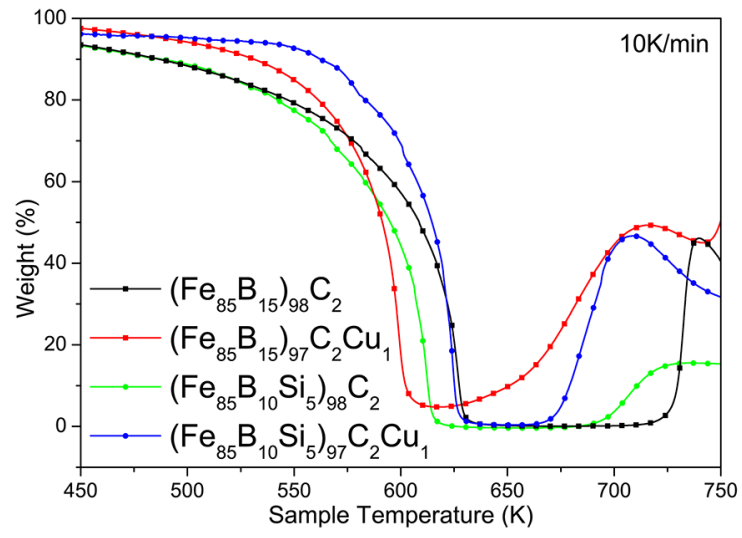

Figure 2. Thermogravimetry curves measurement by TGA, for the systems with different chemical composition, with different content of additions in the base composition. 


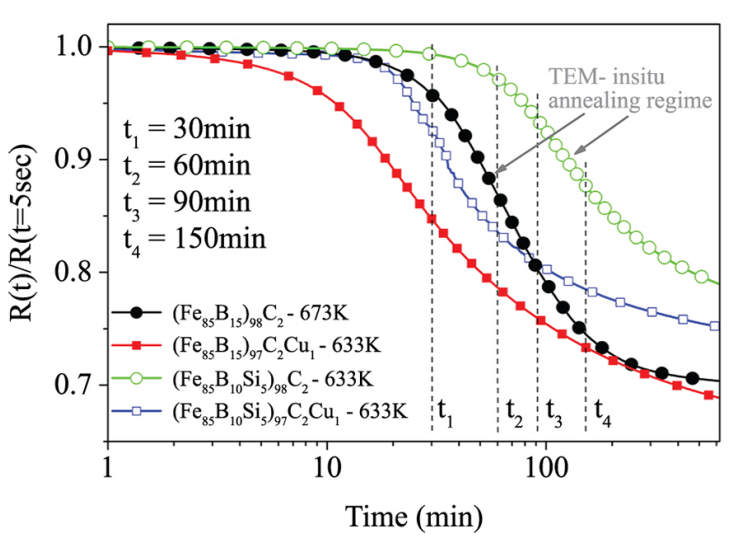

(a)

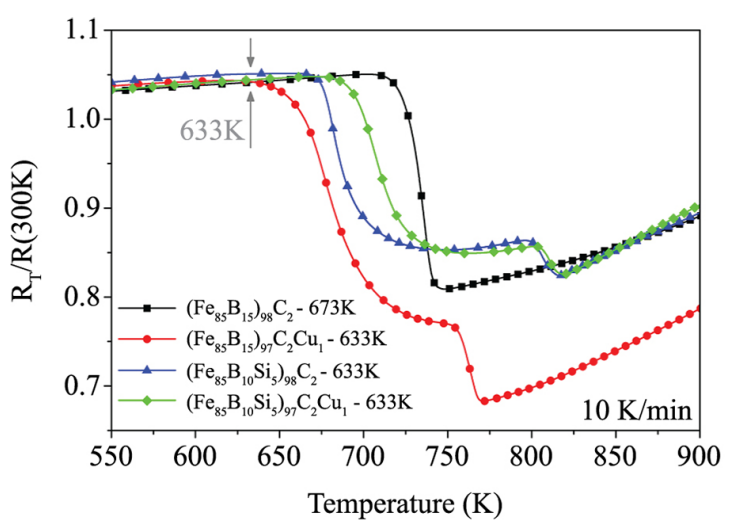

(b)

Figure 3. (a) Temperature dependence of the relative electrical resistivity for the systems with different chemical composition, marked - the temperature chosen for isothermal annealing for XRD analysis. (b) Evolution of relative electrical resistivity for the studied systems during isothermal annealing at $633 \mathrm{~K}$ and $673 \mathrm{~K}$ $\left(\mathrm{t}_{1}=30 \mathrm{~min}, \mathrm{t}_{2}=60 \mathrm{~min}, \mathrm{t}_{3}=90 \mathrm{~min}, \mathrm{t}_{4}=150 \mathrm{~min}\right)$.

The amorphous state of the as-quenched samples was checked by X-ray diffraction. The patterns from ribbons in the as-cast state exhibit only a typically broad hallo, Figure 4. After the isothermal annealing at $633 \mathrm{~K} / 30 \mathrm{~min}$ the samples with Si content exhibit a growing amount of bcc-Fe phase as a product of the first transformation. The phase evolution from the amorphous matrix for selected compositions - the base: Fe-B-C (Figure 5a); and the "full": Fe-B-Si-C-Cu (Figure 5b) was investigated by XRD by in-situ annealing. The obtained XRD maps show clearly the comparison between the "polymorphous" transformation, where bcc-Fe and $\mathrm{Fe}_{3} \mathrm{~B}$ are formed at the same time (Figure 5a), and the two stage transformation (Figure 5b), where the second step- the onset of evolution of $\mathrm{Fe}_{3} \mathrm{~B}$ boride is shown as well.

Kinetics of structural changes has been observed also by resistivity evolution during isothermal annealing, shown in Figure $3 \mathrm{~b}$ for $633 \mathrm{~K}$. For the Fe-B-C sample the higher annealing temperature $-673 \mathrm{~K}$ was used, because this sample exhibits higher temperature of crystallization onset. Thermal regime for the TEM observation by in-situ annealing for the sample Fe-B-C (Figure 6) and Fe-B-Si-C (Figure 7) has been

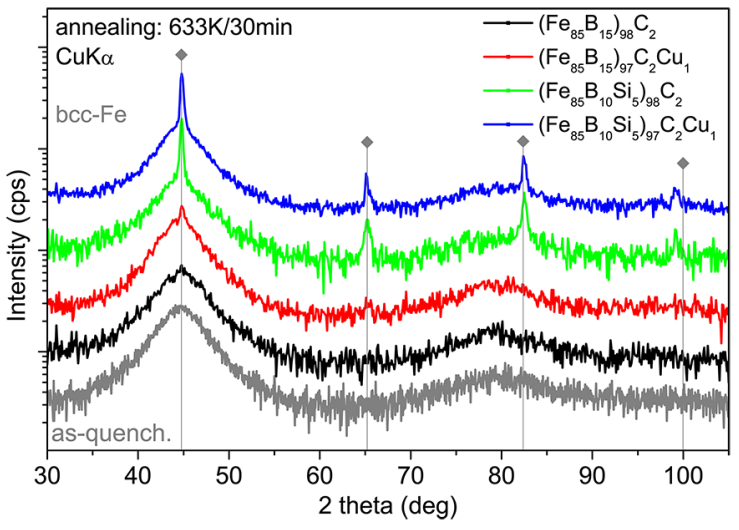

Figure 4. XRD patterns taken from the marked samples in as cast state and after isothermal annealing with interpretation of the diffracted peaks.

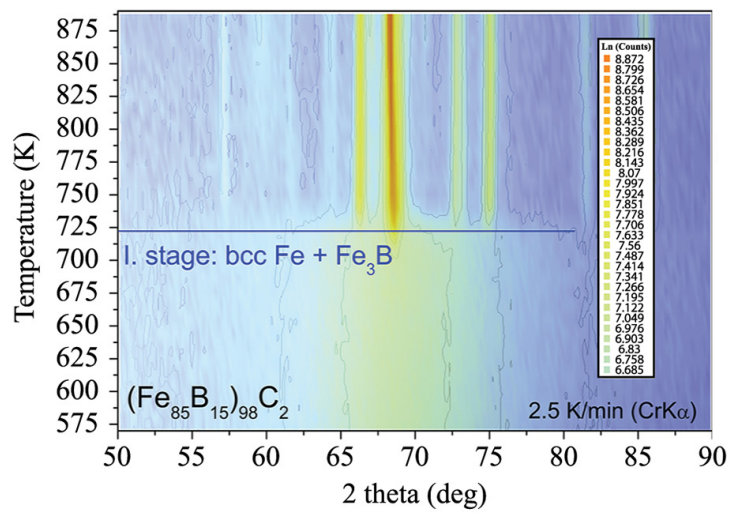

(a)

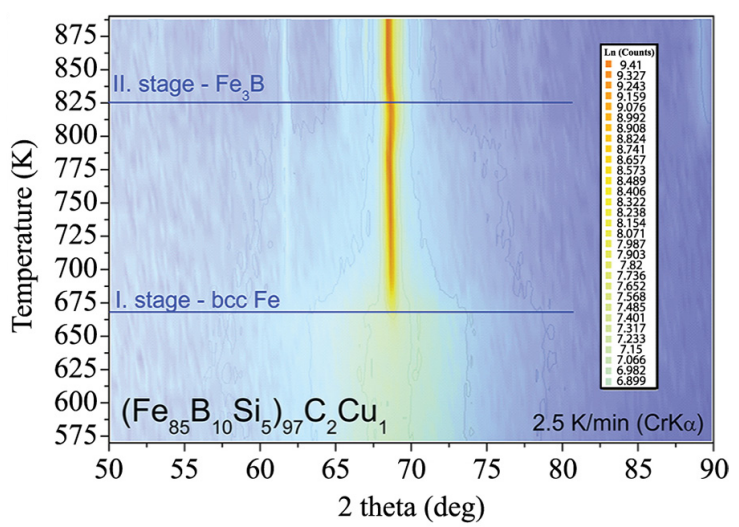

(b)

Figure 5. X-ray diffraction patterns - maps, by in-situ linear annealed samples, with marked phase evolution for sample based on: (a) Fe-B-C. (b) Fe-B-Si-C-Cu.

selected on the basis of the time evolution of crystallization from Figure $3 b$. The aim of this experiment was to monitor the evolution of grain size and morphology with proceeding transformation and the differences due to the addition of $\mathrm{Si}$ into the basic Fe-B-C system. The growth of the crystalline phase at the expense of the amorphous matrix is illustrated in Figure 6. By comparison of the resulting structures the 
effect of Si content is evident: the grains of bcc-Fe are smaller and more regular.

The dependence of activation energy (Figure 8) of crystallization of alpha-Fe during the first stage of transformation of $\left(\mathrm{Fe}_{85} \mathrm{~B}_{10} \mathrm{Si}_{5}\right)_{97} \mathrm{C}_{2} \mathrm{Cu}_{1}$ was calculated according to Švec \&
Kristiakova $^{17}$ using the isothermal resistivity data shown in Figure $8 \mathrm{a}$. The value of $\mathrm{E}_{\mathrm{akt}} \sim 245 \mathrm{~kJ} / \mathrm{mol}$ in Figure $8 \mathrm{~b}$, observed during the major part of crystallization is in excellent agreement with the value obtained from Kissinger analysis (Figure 1b).

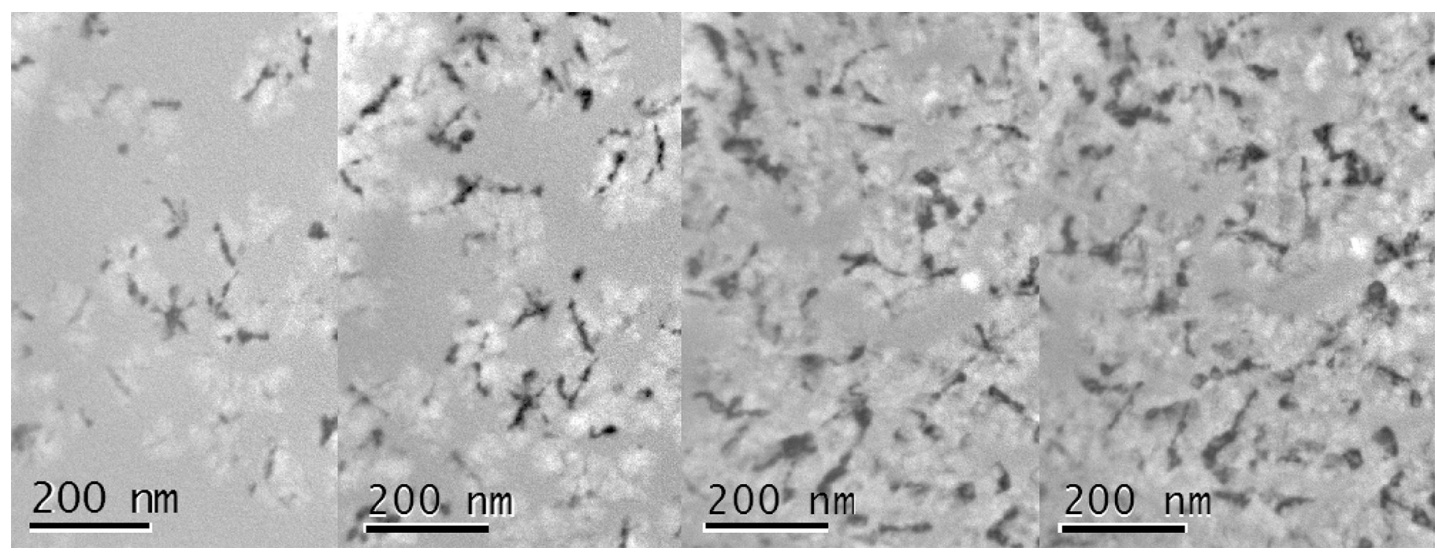

Figure 6. Structure evolution by TEM micrographs of rapidly quenched $\left(\mathrm{Fe}_{85} \mathrm{~B}_{15}\right)_{98} \mathrm{C}_{2}$ system observed during in-situ isothermal annealing $673 \mathrm{~K}$ at the time: $\mathrm{t}_{1}=30 \mathrm{~min}, \mathrm{t}_{2}=60 \mathrm{~min}, \mathrm{t}_{3}=90 \mathrm{~min}, \mathrm{t}_{4}=150 \mathrm{~min}$.

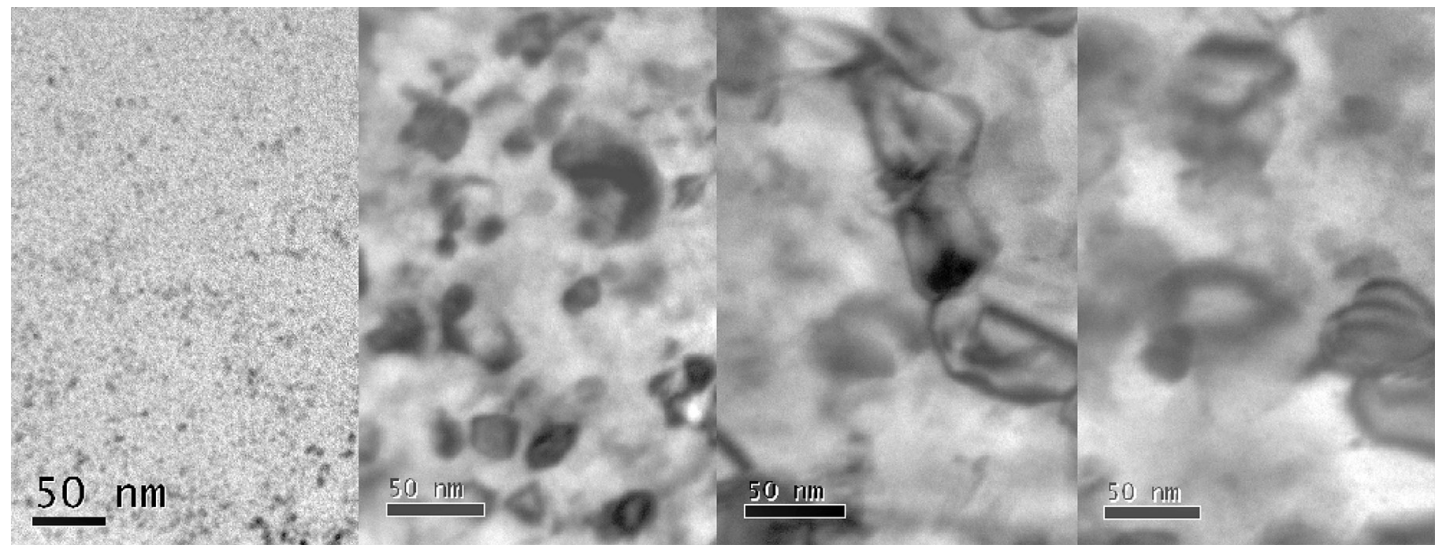

Figure 7. Structure evolution by TEM micrographs of rapidly quenched $\left(\mathrm{Fe}_{85} \mathrm{~B}_{10} \mathrm{Si}_{5}\right)_{98} \mathrm{C}_{2}$ system observed during in-situ isothermal annealing $633 \mathrm{~K}$ in time: $\mathrm{t}_{1}=30 \mathrm{~min}, \mathrm{t}_{2}=60 \mathrm{~min}, \mathrm{t}_{3}=90 \mathrm{~min}, \mathrm{t}_{4}=150 \mathrm{~min}$.

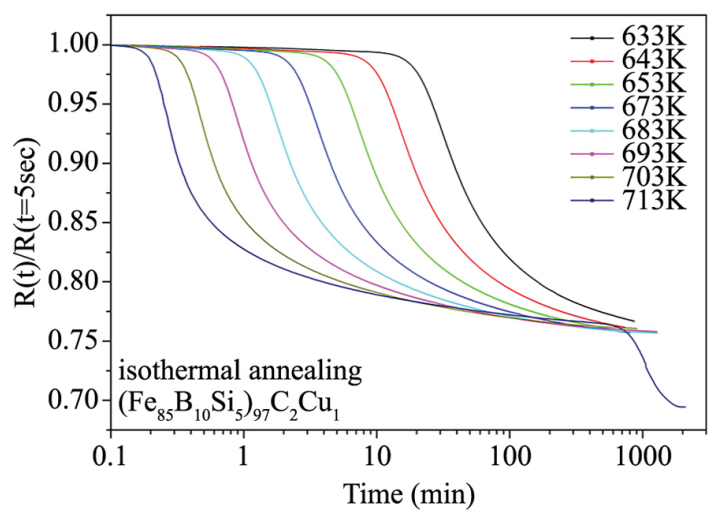

(a)

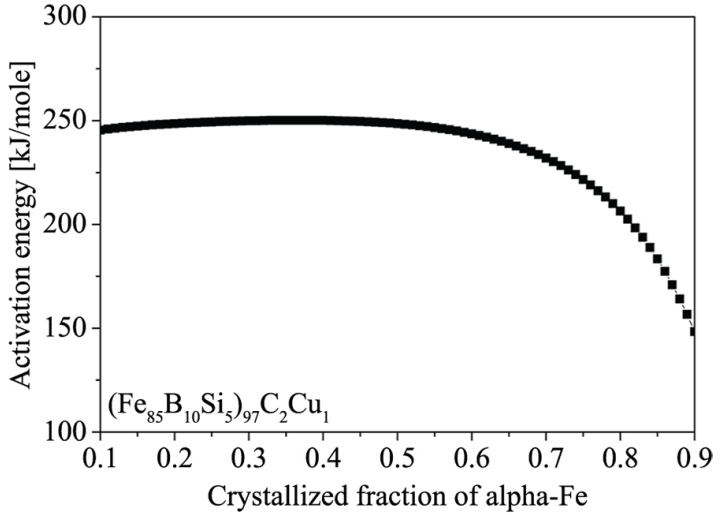

(b)

Figure 8. (a) Evolution of relative electrical resistivity for the Fe-B-Si-C-Cu system during isothermal annealing at marked temperatures. (b) Dependence of activation energy of crystallization of bcc-Fe during the first stage of transformation. 


\section{Conclusion}

The study of transformation of the systems based on Fe-B-(Si)-C-(Cu) has indicated the influence of individual addition or the combination of additions of $\mathrm{Si}$ and $\mathrm{Cu}$ into the basic Fe-B-C system on the grain size morphology and the final structure. This complex metastable system transforms in two stages, as proved by resistivity changes. The exception is the Fe-B-C system where only a single stage transformation occurs. This can serve as a basis for the comparison with similar behavior of Fe-B-P system ${ }^{18,19}$. Different contents of the ferromagnetic bcc-Fe phase are obtained using the same thermal processing depending on the chemical composition of the alloy. The addition of $\mathrm{Si}$ leads to the smaller and more regular bcc-Fe grains, which should guarantee to achieve improved magnetic properties (with low anisotropy) and increase of temperature interval between the two crystallization stages, resulting in a better stability of the ferromagnetic phase and the remaining

\section{References}

1. Yoshizawa Y, Oguma S and Yamauchi K. New Fe-based soft magnetic alloys composed of ultrafine grain structure. Journal of Applied Physics. 1988; 64(10):6044-6046. http://dx.doi. org/10.1063/1.342149.

2. Yoshizawa Y. Magnetic properties and microstructure of nanocrystalline Fe-based alloys. Materials Science Forum. 1999; 307:51-62. http://dx.doi.org/10.4028/www.scientific. net/MSF.307.51

3. Makino A, Hatanai T, Inoue A and Masumoto T. Nanocrystalline soft magnetic $\mathrm{Fe}-\mathrm{M}-\mathrm{B}(\mathrm{M}=\mathrm{Zr}, \mathrm{Hf}, \mathrm{Nb})$ alloys and their aplications. Materials Science and Engineering A. 1997; 226-228:594-602. http://dx.doi.org/10.1016/S0921-5093(96)10693-6.

4. Herzer G. Modern soft magnets: amorphous and nanocrystalline materials. Acta Materialia. 2013; 61(3):718-734. http://dx.doi. org/10.1016/j.actamat.2012.10.040.

5. Willard MA, Claassen JH, Stroud RM and Harris VG. Structure and magnetic properties of $(\mathrm{Co}, \mathrm{Fe})$ - based nanocrystalline soft magnetic materials. Journal of Applied Physics. 2002; 91(10):8420-8422. http://dx.doi.org/10.1063/1.1453946.

6. Yoshizawa Y, Fujii S, Ping DH, Ohnuma M and Hono K. Magnetic properties of nanocrystalline $\mathrm{Fe}-\mathrm{Co}-\mathrm{Cu}-\mathrm{M}-\mathrm{Si}-\mathrm{B}$ alloys (M: Nb, Zr). Materials Science and Engineering A. 2004; 375377:207-212. http://dx.doi.org/10.1016/j.msea.2003.10.227.

7. Willard MA and Daniil M. Nanocrystalline soft magnetic alloys two decades of progress. Handbook of Magnetic Materials. 2013; 21:173-342. http://dx.doi.org/10.1016/B978-0-44459593-5.00004-0.

8. Zhang Z, Sharma $\mathrm{P}$ and Makino A. Role of Si in high Bs and low core-loss $\mathrm{Fe}_{85.2} \mathrm{~B}_{10-\mathrm{X}} \mathrm{P}_{4} \mathrm{Cu}_{0.8} \mathrm{Si}_{\mathrm{X}}$ nano-crystalline alloys. Journal of Applied Physics. 2012; 112(10):103902. http:// dx.doi.org/10.1063/1.4765718.

9. Shih JC, Bourgeois L, Suzuki K and Garitaonandia JS. Grain growth process of two-phase nanocrystalline soft magnetic materials. Journal of Magnetism and Magnetic Materials. 2006; 304(2):693-696. http://dx.doi.org/10.1016/j.jmmm.2006.02.173.

10. Svec P, Janotova I, Vlasak G, Janičkovic D, Marcin J, Kovac $\mathrm{J}$, et al. Evolution of structure and magnetic properties of rapidly quenched $\mathrm{Fe}-\mathrm{B}$ based systems with addition of $\mathrm{Cu}$. IEEE Transactions on Magnetics. 2010; 46(2):408-411. http:// dx.doi.org/10.1109/TMAG.2009.2034333. amorphous matrix, as desired. The addition of $\mathrm{Cu}$ makes a small shift of crystallization onset temperature. The used combination of additions in the Fe-B-Si-C-Cu sample have lead to the required stability increase and also to optimization of activation energy for transformation of the ferromagnetic phase. Therefore, this composition can be considered as perspective for use in practical applications and so that it will be the subject for further more detailed studies.

\section{Acknowledgements}

This work was supported by the Competence Centre for New Materials, Advanced Technologies and Energy, ITMS code 26240220073, supported by the Research and Development Operational Programme funded by the ESDF (75\%). Projects VEGA 2/0189/14, APVV-0492-11, APVV-0647/10, APVV-0460-12 and CEX FUN-MAT are acknowledged for further support.

11. Ohta M and Yoshizawa Y. Magnetic properties of high-Bs $\mathrm{Fe}-\mathrm{Cu}-\mathrm{Si}-\mathrm{B}$ nanocrystalline soft magnetic alloys. Journal of Magnetism and Magnetic Materials. 2008; 320(20):750-753. http://dx.doi.org/10.1016/j.jmmm.2008.04.064.

12. Fan XD, Men H, Ma AB and Shen BL. Soft magnetic properties in $\mathrm{Fe}_{84-} \times \mathrm{B}_{10} \mathrm{C}_{6} \mathrm{Cux}$ nanocrystalline alloys. Journal of Magnetism and Magnetic Materials. 2013; 326:22-27. http://dx.doi. org/10.1016/j.jmmm.2012.08.045.

13. Mat'ko I, Illeková E, Švec P and Duhaj P. Crystallization characteristics in the Fe-Si-B glassy ribbon system. Materials Science and Engineering A. 1997; 225(1-2):145-152. http:// dx.doi.org/10.1016/S0921-5093(96)10567-0.

14. Jen SU and Yang SM. Isothermal crystallization kinetics of amorphous $\mathrm{Fe}_{86} \mathrm{~B}_{14}$ and $\mathrm{Fe}_{82} \mathrm{~B}_{18}$. Journal of Magnetism and Magnetic Materials. 1988; 71(2):165-171. http://dx.doi. org/10.1016/0304-8853(88)90081-9.

15. Blázquez JS, Conde CF, Conde A and Kulik T. A direct extension of the Avrami equation to describe the non-isothermal crystallization of Al-base alloys. Journal of Alloys and Compounds. 2007; 434435:187-189. http://dx.doi.org/10.1016/j.jallcom.2006.08.274.

16. Yuan ZZ, Chen XD, Wang BX and Wang YJ. Kinetics study on non-isothermal crystallization of the metallic $\mathrm{Co}_{43} \mathrm{Fe}_{20} \mathrm{Ta}_{5.5} \mathrm{~B}_{31.5}$ glass. Journal of Alloys and Compounds. 2006; 407(1-2):163169. http://dx.doi.org/10.1016/j.jallcom.2005.06.022.

17. Švec P and Kristiakova K. Crystallization of metallic glasses by continuous distribution analysis. Materials Science Forum. 2001; 360-362:475-480. http://dx.doi.org/10.4028/www. scientific.net/MSF.360-362.475.

18. Janotová I, Švec P, Mat'ko I, Janičkovič D and Švec P Sr. The structure of rapidly quenched $\mathrm{Fe}-\mathrm{Co}-\mathrm{B}-\mathrm{Si}$ based systems and the influence of addition of $\mathrm{Cu}$ and P. Journal of Alloys and Compounds. 2014; 615:S198-S202. http://dx.doi.org/10.1016/j. jallcom.2013.12.044.

19. Janotová I, Hosko J, Švec P, Mat'ko I, Janičkovič D, Švec $\mathrm{P}$ Sr, et al. The study of structure of Fe-B-P based metallic glasses. Applied Surface Science. 2013; 269:102-105. http:// dx.doi.org/10.1016/j.apsusc.2012.10.110.

20. Illeková E. FINEMET-type nanocrystallization kinetics. Thermochimica Acta. 2002; 387(1):47-56. http://dx.doi. org/10.1016/S0040-6031(01)00822-X. 